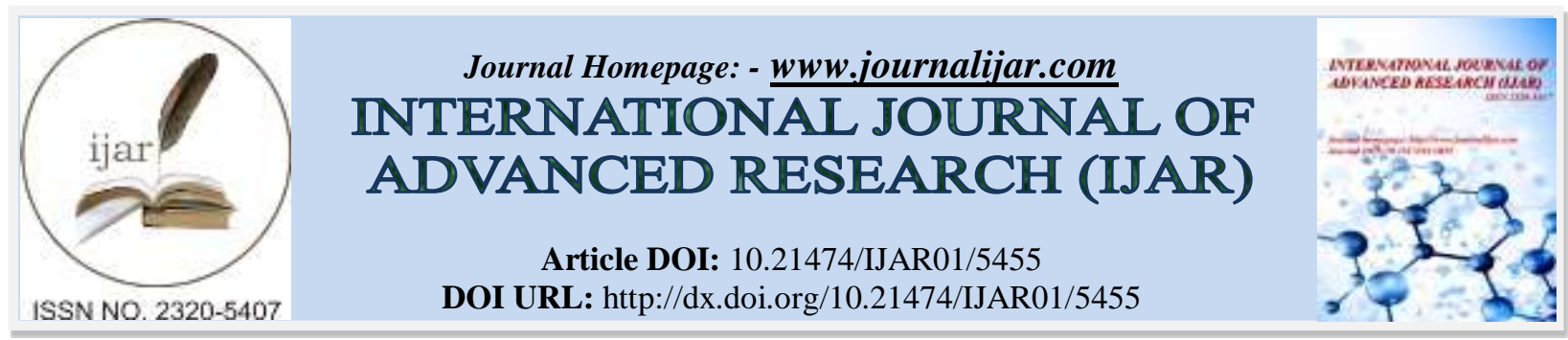

RESEARCH ARTICLE

\title{
ANGIONEUROTIC EDEMA IN A PATIENT WITH HEREDITARY ANGIOEDEMA TYPE I, INDUCED BY AN OPIOID ANALGESIC - A CLINICAL CASE.
}

\section{Dermrndjiev Sv. ${ }^{1}$, Koev K. ${ }^{2}$ and Dermendjiev $\mathrm{T}^{3}$.}

1. Associate professor Dermendjiev Svetlan Mishev M.D., PhD, Occupational diseases and toxicology department, Medical University of Plovdiv, Bulgaria.

2. Associate professor Koev Krassimir Tzonev M.D.,PhD

3. Chair of Emergency Medicine, Department of ophthalmology, Medical University - Sofia, Bulgaria.

4. Associate professor Dermendzhiev Tihomir Mishev M.D., PhD, Department of Microbiology and Immunology, Pharmaceutical faculty, Medical University, Plovdiv, Bulgaria.

\section{Manuscript Info}

(n........................

Manuscript History

Received: 17 July 2017

Final Accepted: 19 August 2017

Published: September 2017

Key words:-

Angioneurotic edema, Hereditary angioedema, Opioid analgesic.

\section{Abstract}

Hereditary angioedema (HAE) is a rare disease with different frequencies for different populations. Etiologically the disease is associated with congenital immune deficiencies in the complement system. It is also known that in the pathogenesis of type I HAE leading position occupies the quantitative deficiency of $\mathrm{C} 1$-esterase inhibitor (C1-INH). Under the influence of various inducing factors, most commonly injuries, invasive procedures, giving birth, stress and others, is triggered a cascade of reactions leading to the activation of the kinin system, the end result of which is the clinical manifestation of angioedema. Drug-induced edemas were also described in the literature, but their pathogenesis differs from that of HAE. In most cases, behind the induced by taking medication swelling, stand allergic mechanisms. Cases of angioedema induced by other factors and developt by other mechanisms were also described. For participants in the etiology and pathogenesis of angioedema adopt a number of other factors such as irritant, physical, toxic, neuro-reflex agents. In our review of the literature, however, the cases with induced by an opioid analgesic angioedema in patients with proven HAE type I are relatively rare.

Therefore we think that the presented clinical case will enrich the knowledge of the etiology and pathogenesis of angioedema and attract the interest of different clinical specialists - allergists, immunologists, ophthalmologists, dermatologists, toxicologists and others.

Copy Right, IJAR, 2017,. All rights reserved.

\section{Introduction:-}

It is known that the pathogenesis of intolerance reactions to drugs includes both allergic and non-allergic (pseudoallergic) mechanisms. In both reactions the clinical picture is a result of mediators released from the mast cell. But while in reagin-mediated (Type I) allergic reactions the release of mediators (usually histamine) is a consequence of the interaction between antigens (mostly drug-hapten or conjugated to protein drug) with antigenspecific $\mathrm{IgE}$, in non-immune (pseudoallergic) reactions the drug is able directly to provoke the release of mediators 
from the mast cells and it happens for much shorter period of time (1). It is also known that after use of ACE inhibitors angioedema is developt as a consequence of increased bradykinin activity due to blocking of angiotensin converting enzyme that normally degrades bradykinin to inactive peptides (1.23). Therefore ACE inhibitors should not be administered in patients with hereditary angioedema.

In the medical literature single cases are reported about angioedema induced in patients professionally exposed to allergens from the environment (3).

\section{Material and methods:-}

\section{Presentation of the case:-}

31 years old man was admitted to the Department of Occupational Diseases performing Clinical Allergology at the University Hospital in Plovdiv with diagnosis Hereditary Angioedema type I. He was observed by a special commission for diagnosis and treatment of congenital immune deficiencies. The patient had replacement therapy with recombinant analogue of the human $\mathrm{C} 1$ esterase inhibitor $(\mathrm{C} 1-\mathrm{INH})$ in adequate doses for his condition. The dynamics of immunological indices for about two years showed levels of C1 INH and C4 in referent values. Since then he was in clinical remission of HAE. The history of the disease and the presented medical records revealed no evidence of systemic or malignant diseases, neither other concomitant pathology. The performed in the ambulatory and hospital paraclinical examinations showed no abnormalities in immuno-allergic status - tables $(1,2)$.

There was no evidence for food, drug and insect allergy. The patient did not suffer from addictions, has not been treated with ACE - inhibitors and drugs from other pharmacological groups that are registered to cause swelling and rashes as undesirable reactions.

Data of the family history in connection with HAE. The deceased father of the patient had episodes of swelling, some of which were quite heavy, without available medical records about the case.

There are no reported risk factors of the working environment. The patient was active smoker - about 10 cigarettes per day for 10 years, without consumption of alcohol.

About an hour after taking the opioid analgesic because of a headache appeared a severe swelling of the face, eyelids, conjunctivas and the neck shoulder region, accompanied by itching.

\section{Physical status:-}

The patient was in preserved general condition. Clear conscious. Adequate. Afebrile. Massive angioneurotic edema of the face and in the neck shoulder region accompanied by bearable itching (photos 1,). In an ophthalmic study, an allergic conjunctivitis with pronounced allergic conjunctival edema and eyelids edema.

Single hives on face, eyelids, neck and shoulder area (photo 2). Tongue and speech - without deviation.

Peripheral lymph nodes were not increased in palpation.

Pulmonary and cardiovascular status - without deviation from normal for their age.

Abdomen at the chest level, soft and non-painful in palpation.

Liver and spleen were not palpated enlarged.

Bone-muscular system properly developed for the age. 


\section{Photo 1}
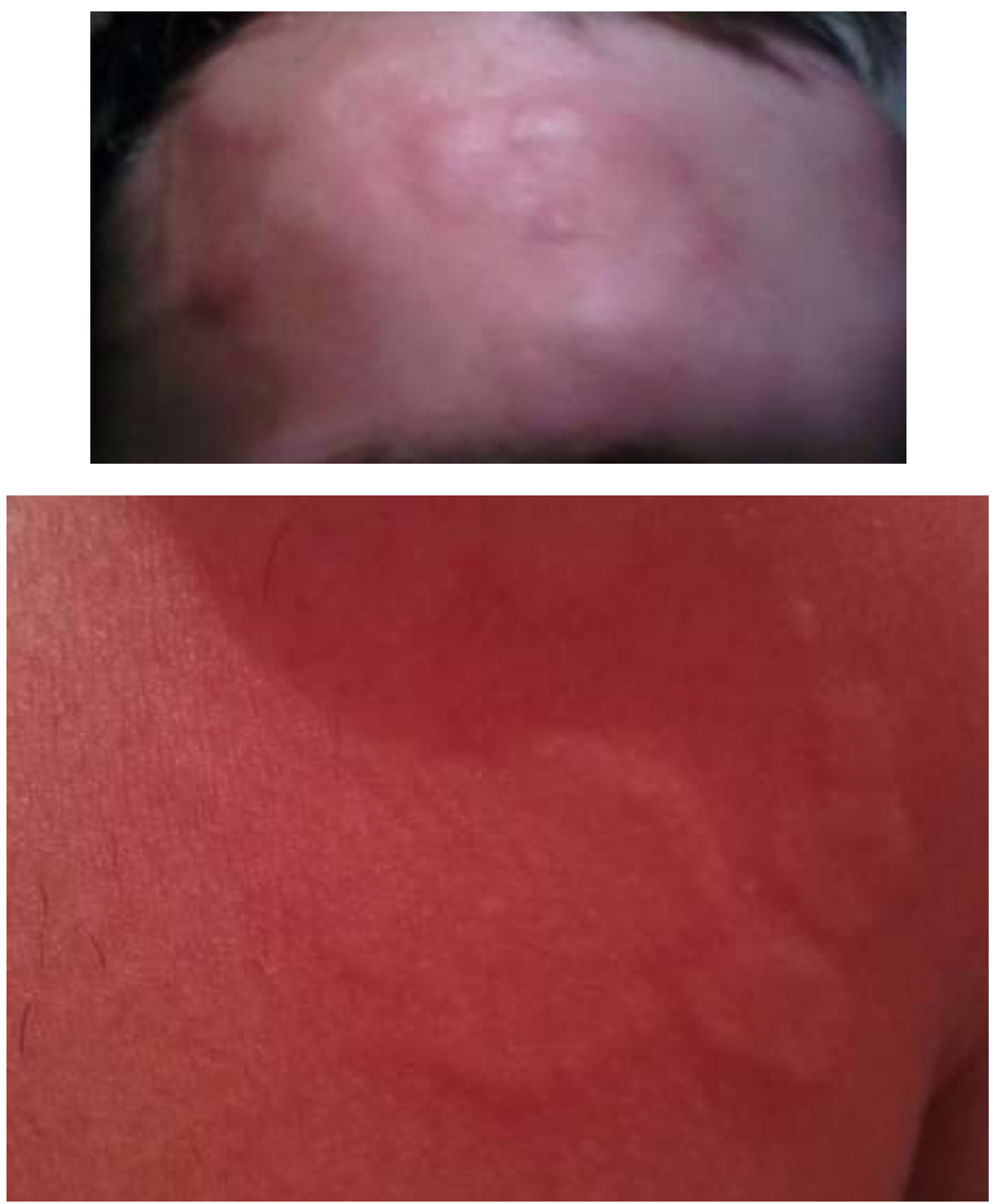

\section{Photo 2.}

Performed diagnostic examinations:

Haematological and biochemical examination were normal.

The performed skin allergic test with a panel of indoor and outdoor allergens was negative for sensibilisation to the tested allergens.

Table 1:- Immunological and serological examinations

\begin{tabular}{|l|l|l|l|}
\hline Test & Method & Result & Reference values \\
\hline $\lg \mathrm{E}$ & ELISA & $\begin{array}{l}70,0 \quad \mathrm{IU} / \mathrm{ml} \\
\text { negative } /-/\end{array}$ & $<100 \mathrm{iu} / \mathrm{ml}$ \\
\hline $\lg \mathrm{G}$ & & $13,700 \mathrm{~g} / 1$ & $6,58-18,37 \mathrm{~g} / 1$ \\
\hline $\lg \mathrm{M}$ & Nephelometry & $0,937 \mathrm{~g} / 1$ & $0,40-2,63 \mathrm{~g} / \mathrm{l}$ \\
\hline $\lg \mathrm{A}$ & Nephelometry & $1,159 \mathrm{~g} / \mathrm{l}$ & $0,71-3,60 \mathrm{~g} / \mathrm{l}$ \\
\hline $\mathrm{C} 3$ serum level & Nephelometry & $1.2 \mathrm{~g} / \mathrm{l}$ & $0.9-1.8 \mathrm{~g} / \mathrm{L}$ \\
\hline $\mathrm{C} 4$ serum level & Nephelometry & $0.25 \mathrm{~g} / 1$ & $0.1-0.4 \mathrm{~g} / \mathrm{L}$ \\
\hline $\mathrm{C} 1$ INH level & Nephelometry & $292 \mathrm{~g} / \mathrm{l}$ & $195-345 \mathrm{~g} / \mathrm{L}$ \\
\hline
\end{tabular}




\begin{tabular}{|l|l|l|l|}
\hline C1 INH activity & Enzyme immuno-assay & $90 \%$ & $70-130 \%$ \\
\hline C1q serum level & ELISA & $170 \mathrm{mg} / \mathrm{L}$ & $149-221 \mathrm{mg} / \mathrm{L}$ \\
\hline ANA (Antinuclear antibody) & Immunofluorescence & $0.8 \mathrm{IU} / \mathrm{mL}$ & $<1.40 \mathrm{IU} / \mathrm{mL}$ \\
\hline CRP & Nephelometry & $0.6 \mathrm{mg} / \mathrm{L}$ & $0-1 \mathrm{mg} / \mathrm{L}$ \\
\hline
\end{tabular}

After the applied therapeutic procedures involving 3 day course of systemic corticosteroids, $\mathrm{H} 1$ and $\mathrm{H} 2$ blockers at doses corresponding to the clinical picture, angioedema and hives underwent full back development. The patient was discharged asymptomatic and in good general condition.

\section{Conclusion:-}

On the grounds of data from the general and specific allergy history, subjective complaints of the patient, allergic and general physical status, results of the clinical examinations, tests, samples and submitted medical documentation, we accepted as a final diagnosis Angioedema in patient with hereditary angioedema type I, induced by taking an opioid analgesic, and accompanying urticaria.

\section{Discussion:-}

It is known that opioid analgesics are among the drugs which induce non immune, also called in the literature pseudoallergic or anaphylactoid reactions (1). The mechanism by which this type of reactions is triggered is connected to direct mast cell degranulation and release of mediators - histamine, tryptase, leukotrienes, PGD2, PAF and other. Some of them possess vasoactive properties and cause dilation of the arterioles and increased permeability of postcapillary venules (1). These processes are the basis for developing of angioedema. On the other hand, the etiology and pathogenesis of hereditary angioedema are also well understood $(1,2,4)$. The location of the edema can vary, most commonly affecting the soft tissue of the face, neck, upper respiratory tract, genital area. In HAE other more unusual locations have also been reported such as abdominal, which may clinically manifest with sudden severe pain imitating an acute abdomen $(1,4)$. Less common site of angioedema is the isolated swelling of the uvula. It can be triggered by two groups of factors - medicines and non-pharmacological agents $(3,5,6,7,11)$. Drugs for which there are reports for inducing this type of edema are inhibitors of the angioconverting enzyme, aspirin, NSAIDs, ipratropium bromide, glucosamine sulfate, opioid analgesics, X-ray contrast agents. From the group of non pharmacological factors that can cause swelling of the uvula are allergens, most oftenly food ("seafood", hazelnuts, walnuts) orotracheal intubation, pharyngo-tonsillar infections, cannabis and others. We reported in our previous publication a rare form of angioedema of the uvula with proved professional etiology (3).

Hereditary angioedema (HAE) type I is a rare disease with different frequencies for different populations. Congenital immune deficiencies in the complement system are etiologically associated with the disease $(1,2,4)$. Its pathogenesis is also known, a leading position in which occupies quantitative deficiency of C1-esterase inhibitor. The last one, under the influence of various precipitating factors, usually trauma, invasive procedures, giving birth, stress, triggers a cascade of reactions leading to the activation of the kinin system, the end result of which is the clinical manifestation of angioedema $(1,4,24)$. The diagnostic and therapeutic algorithms for this rare disease are constantly updated and supplemented $(1,2,4,13,14,17,18,19,20,21,22,24)$.

Therefore in each case with angioneurotic edema, especially in patients with family history, the presented rare form of the disease should be suspected $(1,4,24)$. In our case HAE type I was demonstrated by data from the medical records of the patient and the confirming results from specific diagnostic immunological parameters.

In light of the above considerations, the uniqueness of the presented case should be sought in the possibility in one and the same person to be found combination between allergic and non-allergic mechanisms for developing angioedema. The evidence for this combination was based on the results of the implemented and described above clinical and laboratory diagnostic examinations. HAE was demonstrated with data from medical history, medical records and immunological parameters. The established at the time of the incident normal levels of C1-INH and C4 gave reason to assume that this case did not refer to drug-induced attack of HAE (Table 3). On the other hand, the nature of swelling, the accompanying urticaria and pruritus, the effective influence of the applied corticosteroids and antihistamines were grounds to suspect also an allergic mechanism, despite the absence of objective evidence of sensibilisation. The last was not established because of the negative results of the implemented specific allergy examinations. 
Based on the above considerations, in conclusion we accepted that angioneurotic edema in the presented case should be interpreted as a non immune (pseudoallergic) reaction triggered by taking proven direct histaminoliberator, such as opioid analgesic. This reaction develops on the background of already diagnosed immunodeficiency, in which, as it is known, edemas have another etiology and pathogenesis.

Besides the established in practice paraclinical examinations, the clinical experience is necessary and important condition for the differential diagnosis of these conditions, as the etiology and pathogenetic mechanisms of angioedema and urticaria are variable, but their clinical picture is similar or overlapping.

\section{Conclusions:-}

1. The combination of allergic and non-allergic mechanisms for the development of angioneurotic edema is possible in one and the same patient.

2. Opioid analgesics can induce angioedema (with or without urticaria) in proven HAE type I in the absence of clinical and laboratory evidence of activity of HAE.

3. Because of the similarity in the clinical appearance of different types of angioedema, an accurate establish of their etiology and pathogenesis is needed in connection with the effectiveness of the applied treatment.

\section{References:-}

1. Dimitrov V. - Allergic diseases - principles, diagnosis and treatment. 2000 ARSO, Pages 121-123,175, 157, 171-176

2. Elissaveta Naumova, Iskra Altunkova - Clinical immunology. 2008 Litse, Pages 138-140

3. Dermendjiev S. A rare form of angioedema of the uvula in occupational exposure to paper dust-clinical case. Allergies Hypersensitivity Asthma,2015, 1:87-93

4. Krusheva B. Staevska M. Hereditary angioedema - the path to diagnosis and new therapeutic strategies. Allergies Hypersensitivity Asthma,2016, 2: 11-23

5. Mattingly G., Rodu B., Alling R. - Quincke's disease: nonhereditary angioneurotic edema of the uvula. Oral Surg Oral Med Oral Pathol. 1993 Mar;75(3):292-5

6. C.J. Huang - Isolated Uvular Angioedema in a Teenage Boy. The Internet Journal of Emergency Medicine 2007 Volume 3 Number 2

7. Timothy C. Evans, Raymond J. Roberge - Quincke's disease of the uvula. The American journal of emergency medicine 1987 May;5(3):211-6.

8. Dick C. Kuo, Robert A. Barish - Isolated uvular angioedema associated with ACE inhibitor use. The Journal of Emergency Medicine, Volume 13 Issue 3, May-June 1995

9. Bork K., Meng G., Staubach P., Hardt J. - Hereditary angioedema: new findings concerning symptoms, affected organs, and course. The American Journal of Medicine, Volume 119, Issue 3, Pages 267-274

10. AYS Wong, TW Wong, CC Lau - A case of angioedema involving the tongue and uvula. Hong Kong Journal of Emergency Medicine 2000; 7:162-165

11. E. Alcoceba, M. Gonzalez, P. Gaig, E. Figuerola, T. Auguet, M. Olona - Edema of the Uvula: Etiology, Risk Factors,Diagnosis, and Treatment. J Investig Allergol Clin Immunol. 2010;20(1):80-3

12. Roberts, James R. MD - Acute Angioedema of the Uvula. Emergency Medicine News, July 2001, Volume 23, Issue 7, Pages 7-12

13. Cicardi M, Bork K, Caballero T, Craig T, Li HH, Longhurst H, Reshef A, Zuraw B. Evidence-based recommendations for the therapeutic management of angioedema owing to hereditary $\mathrm{C} 1$ inhibitor deficiency: consensus report of an International Working Group. Allergy. 2012;67:147-157.

14. Munch EP, Weeke B. Non-hereditary angioedema treated with tranexamic acid. A 6-month placebo controlled trial with follow-up 4 years later. Allergy. 1985;40:92-97.

15. Lewis JH. Idiopathic gastric acid hypersecretion: treatment implications for refractory acid/peptic disorders. Aliment Pharmacol Ther. 1991; 5(suppl 1):15-24.

16. Gluszko P, Undas A, Amenta S, Szczeklik A, Schmaier AH. Administration of gamma interferon in human subjects decreases plasminogen activation and fibrinolysis without influencing $\mathrm{C} 1$ inhibitor. J Lab Clin Med. 1994;123:232-240.

17. Cicardi M, Mannucci PM, Castelli R, Rumi MG, Agostoni A. Reduction in transmission of hepatitis C after the introduction of a heat-treatment step in the production of C1-inhibitor concentrate. Transfusion. 1995; 35:209212.

18. Waytes AT, Rosen FS, Frank MM. Treatment of hereditary angioedema with a vapor-heated C1 inhibitor 
concentrate. N Engl J Med. 1996;334: 1630-1634.

19. Cicardi M, Castelli R, Zingale LC, Agostoni A. Side effects of longterm prophylaxis with attenuated androgens in hereditary angioedema: comparison of treated and untreated patients. J Allergy Clin Immunol. 1997;99:194196.

20. Goring HD, Bork K, Späth PJ, Bauer R, Ziemer A, Hintner H, Wüthrich B. Hereditary angioedema in the German-speaking region [in German]. Hautarzt. 1998;49:114-122.

21. Kunschak M, Engl W, Maritsch F, Rosen FS, Eder G, Zerlauth G, Schwarz HP. A randomized, controlled trial to study the efficacy and safety of $\mathrm{C} 1$ inhibitor concentrate in treating hereditary angioedema. Transfusion. 1998;38:540-549.

22. Farkas H, Gyeney L, Gidófalvy E, Füst G, Varga L. The efficacy of short-term danazol prophylaxis in hereditary angioedema patients undergoing maxillofacial and dental procedures. J Oral Maxillofac Surg. 1999;57:404-408.

23. Scheirey CD, Scholz FJ, Shortsleeve MJ, Katz DS. Angiotensin-converting enzyme inhibitor-induced smallbowel angioedema: clinical and imaging findings in 20 patients. AJR Am J Roentgenol. Aug 2011;197(2):393-8.

24. [Guideline] Cicardi M, Aberer W, Banerji A, Bas M, Bernstein JA, Bork K, et al. Classification, diagnosis, and approach to treatment for angioedema: consensus report from the Hereditary Angioedema International Working Group. Allergy. May 2014;69(5):602-16. 